\title{
Norms as a tool for the study of homography
}

\author{
DAVID S. GORFEIN, JEANNE M. VIVIANI, and JOHN LEDDO \\ Adelphi University, Garden City, New York 11530
}

\begin{abstract}
Four continuous word associations to each of 107 homographs were obtained from 50 male and 50 female undergraduates. Included in the word sample were 12 nonhomophonic homographs (heterophones). The data were analyzed to derive two indexes. A dominance score was defined on the basis of the frequency that a particular meaning was associated to each homograph. A stability score was a measure of the likelihood that the continuous associations were consistent with the first associate. Norms were provided for these measures. Comparison of heterophones to homophones indicates that the former are significantly more stable.
\end{abstract}

A large proportion of English words have principal meanings ranging in distinctiveness from shades of meaning that add precision to communication to examples of nonoverlap of the attributes of a single homographic entry with the sole exception of the orthographic representation (e.g., "bass," which denotes specific meanings, i.e., as a fish and in relation to music, and is pronounced as bass or bass to correspond to the meaning). The existence of polysemy has provided a fertile ground for speculation and research for students of language and the structure and utilization of knowledge.

In our review of possible factors that influence performance in situations involving homographs, we find two main factors of interest. One of these has been attended to in a number of studies, this being the variable of associative dominance. Such a measure is defined on the basis of word association data as the proportion of subjects who produce first associations related to a particular meaning of a homograph. A second variable of interest is the stability of the association. One study in the literature has had that variable as its principal focus. Geis and Winograd (1974) define stability on the basis of a repeated testing of the homograph in separate sessions at different times. In the present study, we adopt the procedure of Bilodeau and Howell (1965), asking for continued associations, and define a measure, "stability," on the basis of the sequential probability that associations to a particular homograph differ in their meaning.

The present study also includes a particular class of homographs, those whose meanings have different pronunciations, that is, are nonhomophonic ("heterophones"). Heterophones are of particular interest, because in print they are ambiguous; nevertheless, the meaning referred to by a subject is clear when the subject is required to pronounce the item. (See Warren \& Warren, 1976, for an illustration of this use.) Since

Reprints of this paper are available from David S. Gorfein, Psychology Department, Adelphi University, Garden City, New York 11530. A more complete presentation of the normative data is also available upon request of the unpublished paper, "The Adelphi Homograph Norms." heterophone pronunciation provides excellent pointer readings to their meanings, it is of particular interest to examine how heterophones compare to homographs. They will be useful in our attempts to elucidate polysemy to the extent that they are comparable to homophonic homographs. None of the available norm tables (Cramer, 1970; Geis \& Winograd, 1974; Perfetti, Lindsey, $\&$ Garson, Note 1) provides information on more than a few heterophones.

The sophisticated researcher of traditional human verbal learning and memory must carefully select materials and cautiously seek to apply conclusions only in the realm of the normative frequencies manipulated. The absence of such caution has on more than one occasion led to findings that were misleading, as in the experiments involving mixed vs. unmixed designs (Twedt \& Underwood, 1959). An examination of the literature with respect to homographs indicates, however, little systematic attempt to investigate the range of homography. Although some studies employ either available norms or locally generated norms (cf. Yates, 1978), other studies report that they use homographs whose two meanings "appeared about equal" (Schvaneveldt, Meyer, $\&$ Becker, 1976). Those studies that have employed normative information have tended to restrict their application of the data to a limited range of the possible variations in homographs generally in the $50 \%$ to $65 \%$ range of dominance. Nevertheless, researchers show a strong tendency to generalize their conclusion to the full range of homography. The most systematic attempt to look at the full range of homographs (Tanenhaus, Leiman, \& Seidenberg, 1979) uses dictionary information exclusively, and not cultural norms, in evaluating hypotheses with respect to homograph access.

\section{METHOD}

\begin{abstract}
Materials
A number of words were selected from a variety of sources, including previous norm-gathering attempts (Geis \& Winograd, 1974 ; Perfetti et al. Note 1), that were judged by the experimenters to have two distinct meanings in common use. Materials were selected in an effort to include a full range of ambiguity when words were presented for association without a context sufficient to disambiguate them. A full range of dominance was
\end{abstract}


desired, from words having both meanings of equal frequency to words having one meaning occurring as an association $100 \%$ of the time. Twelve additional homographs ${ }^{1}$ were included that possessed the unique feature that, when they were uttered, the pronunciation was sufficient to disambiguate the two meanings, as in băss, a fish, or bass, a musical sound in the low range. An additional number of words judge by the authors to be relatively nonambiguous were selected as filler items. Three filler words were selected for each homograph. (Subsequent analysis of data obtained indicated several words chosen to be unambiguous were in fact homographic. These were included in the data reported.)

\section{Test Booklets}

Five homographs and 15 filler words were assigned to each test page. The position of the homographs were random on the page with respect to order, and each page was examined to try to minimize the possibility that any of the filler items would be related to either expected meaning of the homographs. Test booklets were created containing seven pages, which in pilot work seemed to be about the number of pages a subject could do in the time available. Three sets of test booklets were prepared to exhaust the item pool. Pages within booklets were in random order.

\section{Procedure}

Subjects were tested in small groups in a classroom. The procedure was similar to that of Bilodeau and Howell (1965). Each subject was given a test booklet that contained seven pages of 20 lines. Each line contained a single word repeated four times, with each repetition followed by an underlined space in which subjects were to write their answer. Subjects had written instructions that appeared on the cover page of the booklet, which also requested they indicate their age and sex. The instructions centered on the cover page are shown in Figure 1. Unlimited time was allowed.

\section{Subjects}

The testing continued until we had 50 male and 50 female students' responses to each of the words under study. Slightly in excess of 150 male and 150 female Adelphi undergraduates under the age of 25 years served in the experiment to fulfill a course requirement. Each student contributed information on about $35-40$ ambiguous words.

\section{Scoring \\ Two raters were employed to score the materials. ${ }^{2}$ A small sample of words were scored by both raters, and since agreement tended to be very high (almost $100 \%$ ), most of the data repre- sent the scoring of a single rater. The rater examined first asso- ciations to each letter string to find classifications for these associations. All but 11 of the 107 homographs could be classi- fied as having two distinct meanings; the others had three or four principal senses.}

\section{RESULTS}

The data were analyzed separately for the 50 male and 50 female subjects and then combined for certain analyses. Two main measures were derived from the raw data. The first was a dominance measure: Each meaning of a homograph was scored with respect to dominance, that is, the percentage of subjects whose first association corresponded to that particular meaning. For example, 38 of the 50 female subjects produced first associations to the homograph "bark" that were related to its meaning as "animal cry." This was considered the primary meaning and received a dominance score of 76 . The 12 remaining subjects' first associations denoted a "tree covering." This was considered the secondary meaning and received a dominance score of 24 . The second was a stability-of-meaning measure: The first association to each homograph determined its dominance. The participant then gave three additional associations to each homograph. The stability score represents the proportion of individuals who did not change the meaning of these additional associations from their first meaning. Thus, in the example above, of the 38 females who had a first association of "animal cry" to "bark," 10 individuals did not alter their meaning over the three remaining associations. The stability score is $15 / 38$ or $40 \%$.

\section{Sex Differences}

Our first comparisons were for the effect of the sex of the subject. For the purpose of this analysis, only the 96 words that could be classified as having two meanings were employed. A correlation coefficient between the male and female norms was obtained and the regressionline predictions from one sex to the other.

The measures of dominance correlated $.953(\mathrm{df}=$ 190 ), and the respective stability scores correlated .806 . The analysis of regression lines predicting dominance score from one sex to the other showed six words having significant $(>2)$ standard residuals from both prediction lines (male from female and vice versa). Of the six, four were cases of more extreme dominance in one sex or the other (see Table 1). Only two items were of opposite polarity: "deed" and "iron."

This booklet contains many words. Look at a word

and write the first word it makes you think of.

The words are printed four times. Write a different

word for each; do not repeat.

Here is an example:

BITTER dweet BITTER wrer BITTER tante BITTER lemex

DO NOT SKIP ANY WORDS. WORK RAPIDLY, BUT LEGIBLY.

WORK FROM LEFT TO RIGHT.

Figure 1. Instructions from cover page. 
Table 1

Items That Differ Between the Sexes

\begin{tabular}{|c|c|c|c|c|}
\hline \multirow{2}{*}{$\begin{array}{l}\text { Homo- } \\
\text { graph }\end{array}$} & \multicolumn{2}{|l|}{ Male } & \multicolumn{2}{|l|}{ Female } \\
\hline & Dominant Sense & Score & Dominant Sense & Score \\
\hline Capital & Major & 66 & Major & 90 \\
\hline Charge & Related to Price & 54 & Related to Price & 80 \\
\hline Deed & Legal Document & 54 & Action & 66 \\
\hline Iron & Metal & 74 & Press Clothes & 62 \\
\hline Mint & Flavor & 68 & Flavor & 96 \\
\hline Pit & Hole & 72 & Hole/Fruit Stone & 50 \\
\hline
\end{tabular}

\section{Dominance and Stability}

Although we obtained slight sex differences as described above, it did not seem necessary to eliminate any items for our analysis of the general relationship between homograph dominance and stability. Accordingly, we combined the performance of the two groups by averaging their respective measures on dominance and stability. The obtained correlation between dominance and stability in the combined sample was $r=.813$ $(\mathrm{df}=190)$. An examination of the line of best fit predicting stability from dominance revealed an interesting effect. Of the 24 points ( 12 items by two response types for each) for the heterophones, 22 fell above the regression line. We therefore analyzed the data separately for the 12 heterophonic and 84 homophonic homographs.

In the case of the 84 homophones, the correlation between dominance and stability $(\mathrm{r}=.838, \mathrm{df}=166)$ indicates that knowledge of dominance will enable us to account for $70 \%$ of the variance in the stability measure. Similarly, for the 12 heterophones, the obtained correlation $(\mathrm{r}=.845, \mathrm{df}=22)$ accounts for $70 \%$ of the variance in the much smaller number of cases.

Table 2 presents the norms for the combined male and female samples. Examination of the scores clearly shows that the heterophone items are more stable in meaning than are items of equal dominance.

\section{Regional Differences}

Geis and Winograd (1974) have provided norms for Emory University (Atlanta, Georgia) for 50 homographs based on the responses of 68 undergraduates (sex unspecified). Of these 50 items, 45 had been included in norms gathered at Adelphi. However, two words had been eliminated on the basis of pilot work: "sage," since less than $75 \%$ of Adelphi undergraduates could produce a single classifiable association to that string, and "volume," which had elicited three distinct meanings in a pilot study. Three additional words, "club," "sole," and "toll" had produced four, three, and three distinct meanings, respectively, at Adelphi and, therefore, were omitted from the comparison. It should be noted that Geis and Winograd report only the classification of the first two associations in terms of dominance in their table.

A total of 42 words ( 84 meanings) remained common to the two studies. The obtained correlation (.904) for dominance was quite satisfactory. The regression line predicting Emory scores from the Adelphi sample was computed, and those items that showed a high standard residual ( 2 or greater) were examined for the nature of the difference. Three such items were discovered: "organ," "pot," and "right." Of these, the word "organ" was not quite as extremely polarized toward "musical instrument" in the Adelphi sample, whereas the other two showed reversal in dominant meaning. While "pot" produced first associations that can be classified as "kitchen utensil" in 77\% of the Emory sample, $52 \%$ of the Adelphi group produced associations related to "marijuana." Finally, "right" produced a preponderance $(82 \%)$ of associations scorable as meaning "correct" in the Atlanta sample, but $65 \%$ of the Long Island sample produced responses to "right" as a "direction" (i.e., as opposed to "left").

The Pittsburgh norms of Perfetti et al. (Note 1), based on a sample of 100 undergraduates, overlapped

Table 2

Dominance and Stability Scores for 96 Homographs

\begin{tabular}{|c|c|c|c|c|c|c|}
\hline Homograph & Primary Meaning & Dominance & Stability & Secondary Meaning & Dominance & Stability \\
\hline ADMIT & Acknowledge & 65 & 60 & Let In & 35 & 51 \\
\hline ARMS & Appendages & 94 & 82 & Weapons & 6 & 17 \\
\hline ARTICLE & Written Piece & 74 & 72 & Item & 26 & 15 \\
\hline BAND & Group of People & 84 & 65 & Circular Strip & 16 & 0 \\
\hline BANK & Depository & 99 & 93 & River Side & 1 & 0 \\
\hline BARK & Animal Cry & 78 & 33 & Tree Cover & 22 & 14 \\
\hline BASS* & Instrument & 69 & 72 & Fish & 31 & 61 \\
\hline BAT & Baseball Bat & 54 & 29 & Animal & 46 & 45 \\
\hline BEAM & Ray of Light & 67 & 48 & Timber & 33 & 58 \\
\hline BLACKJACK & Card Game & 94 & 77 & Bludgeon & 6 & 57 \\
\hline BOIL & Bubble & 97 & 86 & Sore & 3 & 0 \\
\hline BOWL & Concrete Object & 55 & 56 & Game & 45 & 53 \\
\hline BOXER & Fighter & 82 & 73 & Dog & 18 & 0 \\
\hline BREAD & Bakery Product & 94 & 84 & Money & 6 & 0 \\
\hline BRIDGE & Construction & 79 & 86 & Card Game & 21 & 10 \\
\hline CABINET & Furniture & 95 & 93 & Council & 5 & 40 \\
\hline CALF & Baby Cow & 72 & 68 & Leg Muscle & 28 & 4 \\
\hline CAPITAL & Major & 79 & 70 & Assets & 21 & 19 \\
\hline CHANGE & Alteration & 50 & 50 & Coins & 50 & 14 \\
\hline
\end{tabular}


Table 2 Continued

\begin{tabular}{|c|c|c|c|c|c|c|}
\hline Homograph & Primary Meaning & Dominance & Stability & Secondary Meaning & Dominance & Stability \\
\hline CHARGE & Price & 67 & 34 & Attack & 33 & 48 \\
\hline CLOSE* & Shut & 51 & 62 & Near & 49 & 71 \\
\hline $\mathrm{COACH}$ & Instructor & 65 & 75 & Type of Transportation & 35 & 46 \\
\hline COAT & Article of Clothing & 94 & 81 & Cover & 6 & 0 \\
\hline CONDUCT* & Behavior & 62 & 62 & Guide & 38 & 58 \\
\hline CONTENT* & Happy & 54 & 76 & Ingredient & 46 & 70 \\
\hline COUNT & Add Numbers & 80 & 45 & Nobility & 20 & 0 \\
\hline DEED & Action & 57 & 37 & Legal Document & 43 & 60 \\
\hline DIAMOND & Jewel & 98 & 96 & Ball Field & 2 & 0 \\
\hline DOVE* & Bird & 95 & 97 & Past Tense of Dive & 5 & 40 \\
\hline DUCK & Animal & 96 & 92 & Dodge & 4 & 25 \\
\hline EARTH & Planet & 73 & 74 & Dirt & 27 & 4 \\
\hline EXPRESS & Mode of Transportation & 92 & 72 & Articulate & 8 & 50 \\
\hline FANCY & Elegant & 100 & 96 & Idea & 0 & 0 \\
\hline FAST & Quick & 98 & 86 & Hunger & 2 & 0 \\
\hline FENCE & Enclosure & 93 & 80 & Sport & 7 & 25 \\
\hline FIRM & Strong & 87 & 72 & Company & 13 & 7 \\
\hline FLOUNDER & Fish & 96 & 63 & Be Unsteady & 4 & 75 \\
\hline GRAVE & Burial Place & 98 & 84 & Serious & 2 & 0 \\
\hline HEAD & Body Part & 98 & 82 & Chief & 2 & 0 \\
\hline HIDE & Conceal & 89 & 72 & Animal Skin & 11 & 45 \\
\hline HOST & Entertain & 93 & 82 & Eucharist & 7 & 43 \\
\hline IRON & Metal & 56 & 57 & Press Clothing & 44 & 45 \\
\hline LEAD* & Direct & 53 & 74 & Metal & 47 & 53 \\
\hline LEAN & Without Fat & 66 & 53 & Incline & 34 & 32 \\
\hline LETTER & Communication & 85 & 81 & Alphabet & 15 & 7 \\
\hline LIE & Falsehood & 78 & 65 & Recline & 22 & 18 \\
\hline LIKE & Affection & 91 & 74 & Similar & 9 & 44 \\
\hline LIMP & Lame Walk & 67 & 85 & Not Stiff & 33 & 63 \\
\hline MAD & Angry & 58 & 52 & Crazy & 42 & 20 \\
\hline MARCH & Month & 57 & 19 & Walk & 43 & 14 \\
\hline MATCH & Fire Stick & 62 & 42 & Pairing Act & 38 & 29 \\
\hline MEAL & Food & 98 & 96 & Grain & 2 & 0 \\
\hline MINT & Flavor & 82 & 73 & Money Mint & 18 & 0 \\
\hline MINUTE* & Unit of Time & 90 & 78 & Tiny & 10 & 60 \\
\hline MOLD & Fungus & 60 & 45 & Shape & 40 & 68 \\
\hline MUG & Container & 80 & 54 & Assault & 20 & 20 \\
\hline ORGAN & Musical Instrument & 62 & 44 & Body Part & 38 & 46 \\
\hline PAGE & Leaflet & 90 & 61 & Messenger & 10 & 0 \\
\hline PALM & Type of Tree & 55 & 31 & Part of Hand & 45 & 42 \\
\hline PARK & Recreational Area & 87 & 84 & Leave & 13 & 15 \\
\hline PEN & Writing Pen & 98 & 85 & Enclosure & 2 & 0 \\
\hline PERCH & Mount & 82 & 78 & Fish & 18 & 33 \\
\hline PICK & Instrumental Act & 86 & 73 & Tool & 14 & 14 \\
\hline PIT & Hole & 61 & 49 & Fruit Stone & 39 & 18 \\
\hline PITCHER & Ball Player & 53 & 20 & Container & 47 & 23 \\
\hline PLAY & Recreational Activity & 93 & 90 & Drama & 7 & 29 \\
\hline POKER & Card Game & 98 & 83 & Metal Rod & 2 & 50 \\
\hline PORT & Commercial Port & 87 & 67 & Wine & 13 & 0 \\
\hline POT & Marijuana & 51 & 18 & Container & 49 & 39 \\
\hline PRIVATE & Personal & 97 & 94 & Military Status & 3 & 0 \\
\hline PUPIL & Student & 63 & 52 & Part of Eye & 37 & 5 \\
\hline RACE & Speed Contest & 75 & 77 & Ethnic Group & 25 & 32 \\
\hline RASH & Skin Eruption & 92 & 88 & Hasty & 8 & 25 \\
\hline REFUSE* & Deny & 86 & 83 & Waste & 14 & 57 \\
\hline RIGHT & Direction & 64 & 16 & Correct & 36 & 19 \\
\hline RING & Circular Form & 84 & 54 & Sound & 16 & 25 \\
\hline SCOTCH & Drink & 79 & 61 & Nationality & 21 & 5 \\
\hline SEAL & Animal & 57 & 51 & To Close & 43 & 42 \\
\hline SEASON & Time of Year & 98 & 86 & Flavoring & 2 & $\mathbf{0}$ \\
\hline SECOND & Ordinal Number & 60 & 53 & Unit of Time & 40 & 33 \\
\hline SENTENCE & Grammar Unit & 93 & 89 & Penalty & 7 & 0 \\
\hline SHIFT & Change & 90 & 80 & Time Period & 10 & 40 \\
\hline SOW* & Plant & 79 & 84 & Pig & 21 & 60 \\
\hline STABLE & Animal Pen & 67 & 34 & Steady & 33 & 48 \\
\hline STERN & Strict Discipline & 75 & 79 & Boat Part & 25 & 20 \\
\hline SWALLOW & Gulp & 74 & 72 & Bird & 26 & 12 \\
\hline TABLE & Furniture & 100 & 95 & Schedule & 0 & 0 \\
\hline
\end{tabular}


Table 2 Continued

\begin{tabular}{|c|c|c|c|c|c|c|}
\hline Homograph & Primary Meaning & Dominance & Stability & Secondary Meaning & Dominance & Stability \\
\hline TEAR* & Cry & 72 & 76 & $\operatorname{Rip}$ & 28 & 61 \\
\hline TIRE & Vehicle Part & 96 & 86 & Grow Weary & 4 & 0 \\
\hline TOP & High Point & 84 & 60 & Toy & 16 & 6 \\
\hline TRAIN & Transportation Vehicle & 100 & 95 & Teach & 0 & 0 \\
\hline WATCH & Time Piece & 73 & 27 & Look Out for & 27 & 19 \\
\hline WIND* & Weather & 96 & 97 & Twist & 4 & 0 \\
\hline WOUND* & Injury & 90 & 93 & Past Tense of Wind & 10 & 29 \\
\hline YARD & Three Feet & 61 & 26 & Plot of Land & 39 & 49 \\
\hline YARN & Thread & 95 & 88 & Story & 5 & 0 \\
\hline
\end{tabular}

Note-Sample size $(N=100)$ is maximum score.

${ }^{*}$ Heterophone (i.e., homograph for which pronunciation depends on meaning).

the Adelphi sample of homographs quite substantially (50 items) even when words that had produced more than two meanings had been eliminated.

Once again, we see a fair degree of commonality in response, although the correlation of dominance measures $(r=.825)$ was somewhat smaller than between Adelphi and Emory. A test of deviations from the regression line predicting Pittsburgh dominance from Adelphi again showed three items with large standard residuals: "express," "park," and "right." The last followed the same pattern as the Emory-Adelphi difference, with "right" meaning "correct" being the predominant (91\%) response in the Perfetti et al. norms. "Express," as opposed to "local," was seen as a form of transit by $92 \%$ of the Adelphi population, but only $48 \%$ of the Pittsburgh group produced a first association in that direction. Finally, "park" tended to connote a recreational area for the New Yorkers (87\%), whereas 55\% of the Pittsburgh sample saw it in relation to the act of leaving a car.

A closer examination of the individual items (see Table 3) indicates that there are five items that differed markedly in dominance between our sample and those of the other two schools: "organ," "pot," "right," "express," and "park." Of the five, the Emory and Adelphi samples differed to a large degree on all but one word, "park," and the Pittsburgh and Adelphi samples differed on the three cited: "express," "park," and "right."

A major purpose of the present study was to provide materials for the explanation of the relationship between dominance and stability. In addition to their association measure, Geis and Winograd (1974) report a test-retest measure for semantic sense of associations. This would be equivalent to a stability score based on a change from first to second association in our norms, except that our subjects were required to produce more than one association, whereas Geis and Winograd's group could produce the same word on each occasion of testing. The semantic context of association was free to change in the Geis and Winograd norms from test to retest (the homograph was embedded in different words); in continuous association, any change in meaning must be self-generated. Nevertheless, for comparison purposes, we computed a second stability measure (Stability 2), the likelihood of no change in meaning from the first to second association by our subjects. The correlation between stability and Stability 2 for the 42 items ( 84 meanings) was .84 .

The correlations between the Adelphi stability scores (stability and Stability 2) and the Emory test-retest measure, although statistically reliable, were fairly small $(r=.54$ and $r=.41$, respectively). In fact, the Geis and Winograd (1974) dominance score correlated more highly with the Adelphi score we have labeled stability $(r=.75)$ than it did with the Emory stability score $(r=.64)$. An examination of only the high dominant meanings of the homographs show that the Geis and Winograd words showed an overall tendency to keep the same meaning on retest of $85 \%$ and $82 \%$ of the Adelphi sample kept meaning constant from their first to second association. Since these words showed a mean stability index of $65.5 \%$, this indicates that about $52 \%$ of the words that will change meaning at all do so on the first opportunity.

Table 3

Five Items Showing High Standard Residual in Using Adelphi Norms as a Predictor

\begin{tabular}{|c|c|c|c|c|c|c|}
\hline \multirow[b]{2}{*}{ Word } & \multicolumn{2}{|l|}{ Adelphi } & \multicolumn{2}{|l|}{ Emory } & \multicolumn{2}{|c|}{ Pittsburgh } \\
\hline & Dominant Sense & Percent & Dominant Sense & Percent & Dominant Sense & Percent \\
\hline Express & Mode of Transport & 92 & Articulate & $52^{*}$ & Mode of Transport & $63^{*}$ \\
\hline Organ & Musical Instrument & 62 & Musical Instrument & $90^{*}$ & Musical Instrument & 59 \\
\hline Park & Recreational Area & 87 & Recreational Area & 60 & Leave Car & $55^{*}$ \\
\hline Pot & Marijuana & 51 & Kitchen Utensil & $77^{*}$ & Marijuana & 55 \\
\hline Right & Direction & 64 & Correct & $82^{*}$ & Correct & $91^{*}$ \\
\hline
\end{tabular}

*High standard residual compared to Adelphi. 


\section{DISCUSSION}

\section{The Norms}

The major purpose of this study was to achieve a set of norms for homographs that would provide a range of materials for investigators of language. Homographs were viewed as varying in two ways that were potentially of importance in understanding meaning. Homographs vary in both their tendency to elicit an initial response related to a particular interpretation (dominance) and their tendency to maintain that meaning over subsequent associative attempts (stability).

The range of dominance in the norms for homographs varies quite nicely, with at least 10 words through each $10 \%$ of dominance, thus providing a full range of alternatives for the investigator. Our comparisons with other samples (South at Emory, and Mideast at University of Pittsburgh) indicates that while there are some regional differences, the degree of consistency is high enough to apply these norms to other college samples. It is suggested that the experimenter could detect some of the regional differences by examination. (The investigator will be, in most cases, a member of the language group; for example, the word "TAP" in New York is an acronym for Tuition Assistance Plan and, hence, has three meanings regionally.)

\section{Heterophones}

Because of the relationship between meaning and pronunciation, those nonhomophonic homographs called heterophones appear ideal for investigations of language and, in particular, the effects of semantic context on meaning. However, the comparison of these words in our norms suggests the need for some degree of caution in generalizing from heterophones to other words of the language. It is clear from the examination of our data that once a particular meaning is achieved, heterophones are significantly more stable than other homographs of equal dominance. How this might affect performance in language-based tasks would seem to be a fertile topic for investigation.

The basis of the heterophonic distinction in stability may be based on form of acquisition. To the degree that language is acquired aurally, it should not be surprising that the pronunciation difference is accompanied by a much higher degree of stability than that obtained for homographs of equal dominance. It could be interesting to compare this effect with norms from congenitally deaf individuals of the same degree of education. It should be noted that subjects in this study were not required to pronounce the items when producing their written associations to the printed stimuli.

\section{Dominance and Stability}

The correlation between dominance and stability is quite high in this study. Possibly, the true correlation is even higher, if we consider the unreliability in the com- putation of the stability metric. The stability score is essentially a conditional probability; that is, it is based on the fact that one meaning has already been chosen, and it is the likelihood of change to the other meaning. In the case of the low end of the dominance scale, it would be based on only a small number of cases, and thus a small change in absolute frequency of change would produce a large change in stability. At the low end of the distribution, values obtained from the regression line might be a better estimate of the stability score of an item than the actual value in the study sample is.

The significant correlation of dominance and stability is consistent with the results reported by Geis and Winograd (1974), although our use of shifts in continuous association as a measure of stability differs from their measure of test-retest reliability. That stability and dominance are correlated for test and retest had also been established for nonhomographs in continuous association by Szalay and Deese (1978). Similar findings have been obtained for discrete associations (Howes, 1957).

\section{Norms as Cultural Indicants}

The norms themselves can serve as indicators of the knowledge of the (language) cultural group. Szalay and Deese (1978) have produced detailed arguments for this use of word association across languages. In our fairly cursory analysis of the data drawn from three universities, we have been able to detect some interesting differences and identify a large base of common understanding. Since the purpose of the present study was not a sociology of language, we will leave further analysis to those students and merely suggest that the available norms are well worth examining.

\section{Further Research Required}

As we mentioned in the introduction, while the question of the language use of homographs has been broad, little has been done to examine the range of polysemy. Studies that have purported to support dual access models of comprehension (i.e., initially, multiple meanings of a homograph are available, and then, the appropriate one is selected) are particularly vulnerable to artifact (see Hogaboam \& Perfetti, 1975). A recent study of context effects, which seems to distinguish between a single appropriate meaning being available most of the time with an occasional lapse to the nonappropriate meaning and dual access all the time, is that of Onifer and Swinney (1981). Nevertheless, a test of the dual availability hypotheses with the full range of dominance (stability?) would enable us to distinguish which of these alternative possibilities are supported for all levels of dominance (stability). In the case of this occasional lapse hypothesis, the likelihood of a lapse to the nonprimed sense should be an inverse function of the dominance (stability) of the item tested. If high-dominant (95\%) in-context items elicit as much secondary meaning as do 
low-dominant (5\%) in-context words, then the dual access hypothesis will have received convincing support.

Finally, the correlation between dominance and stability is quite high. A study making use of partial correlations or other regression techniques will be necessary to evaluate whether the two have separate psychological import. Of particular interest will be the relationship of the two variables to the differential effect of postambiguity interval reported by Onifer and Swinney. In their study, the meaning unrelated to context quickly loses its priming effect. Conceivably, rate of loss could be related to stability of meaning.

\section{REFERENCE NOTE}

1. Perfetti, C. A., Lindsey, R., \& Garson, B. Association and uncertainty: Norms of association to ambiguous words. Unpublished manuscript, University of Pittsburgh, Learning Research and Development Center, 1971.

\section{REFERENCES}

Bilodeau, E. A., \& Howell, D. C. Free association norms by discrete and continuous methods. Washington, D.C: Office of Naval Research, 1965.

Cramer, P. A study of homographs. In L. Postman \& G. Keppel (Eds.), Norms of word association. New York: Academic Press, 1970.

Geis, M. F., \& Winograd, E. Norms of semantic encoding and availability for fifty homographs. Bulletin of the Psychonomic Society, 1974, 3, 429-431.

Hogaboam, T. W., \& Perfetti, C. A. Lexical ambiguity and sentence comprehension. Journal of Verbal Learning and Verbal Behavior, 1975, 14, 265-274.

Howes, D. On the relation between the probability of a word as an association and in general linguistic usage. Journal of Abnormal and Social Psychology, 1957, 54, 75-85.

Onifen, W., \& Swinney, D. A. Accessing lexical ambiguities during sentence comprehension: Effect of frequency of meaning and contextual bias. Memory \& Cognition, 1981, 9, 225-236.

Schvaneveldt, R. W., Meyer, D. E., \& Becker, C. A. Lexical ambiguity, semantic context, and visual word recognition. Journal of Experimental Psychology: Perception and Performance, 1976, 2, 243-256.

Szalay, L. B., \& Deese, J. Subjective meaning and culture: An assessment through word association. Hillsdale, N.J: Erlbaum, 1978.

Tanenhaus, M. K., Leiman, J. M., \& Seidenberg, M. S. Evidence for multiple stages in the processing of ambiguous words on syntactic contexts. Journal of Verbal Learning and Verbal Behavior, 1979, 18, 427-440.

TwedT, H. M., \& Unde RWood, B. J. Mixed vs. unmixed lists in transfer studies. Journal of Experimental Psychology, 1959, 58, 111-116.

Warren, R. E., \& Warren, N. T. Dual semantic encoding of homographs and homophones embedded in context. Memory \& Cognition, 1976, 4, 586-592.

YATES, J. Priming dominant and unusual senses of ambiguous words. Memory \& Cognition, 1978, 6, 636-643.

\section{NOTES}

1. We wish to thank Michael Hillinger for supplying his lists. 2. We wish to acknowledge the assistance of Betty Dittmar in the tabulation of the data.

(Received for publication September 24, 1981; revision accepted April 20, 1982.) 